\title{
Vaginal hysterectomy and training
}

\author{
Joan Melendez
}

Published online: 20 December 2014

(C) The International Urogynecological Association 2014

Dear Editor,

I read with great interest the article by Moen and Richter "Vaginal hysterectomy: past, present and future" [1].

Vaginal hysterectomy remains a key operation in gynaecology, known to have the quickest recovery time with risks and complication rate comparable to other approaches [2]. These advantages have been maximized when associated with enhanced recovery programmes. Patients after vaginal hysterectomy can be discharged home in as little as $8 \mathrm{~h}$ and hospitals can save up to $£ 300$ per patient with no increase in complications or reduction in patient satisfaction [3].

Scientific evidence like this should help convince both clinicians and managers alike of the advantages of the vaginal approach. Moreover, it should motivate practicing gynaecologists to embrace underused strategies such as the use of GnRH analogues to reduce the size of the uterus and convert a potential abdominal hysterectomy into a vaginal procedure [4].

For the next generation of gynaecologists, though, the problem may be different. The lack of experience and the low numbers of surgical cases we encounter during our training will make it difficult not only to develop but also to maintain our surgical skills.

Blaming the EU's Working Time Directive for this problem is not necessarily accurate, since we know that interventions such as the Mirena IUS, endometrial ablation or operative hysteroscopy have drastically reduced the number of hysterectomies needed to treat benign conditions.

In this day and age trainees have to work in a smarter way and cannot rely on the historical apprenticeship model. We

A response to these comments can be found at doi: 10.1007/s00192-0142612-6.

J. Melendez $(\bowtie)$

Royal Free Hospital, Pond Street, London NW3 2QG, UK

e-mail: joan.melendez@nhs.net have to find other means to develop and maintain our skills and simulation is playing an important role in filling that gap.

There is good evidence that laparoscopic skills can be learned in the simulation centre and successfully translated into the operating theatre. Trainees can become proficient more quickly and achieve better results if they spend hours with the laparoscopic simulator before facing a real patient in theatre [5]. Will the possibility of regular training outside the operating theatre in laparoscopic surgery be a key factor in the way we approach hysterectomies? In the future, with simulators accessible in most units, will it not be easier to practice and attain proficiency in laparoscopic hysterectomy as opposed to vaginal or even abdominal hysterectomy?

Conflicts of interest None.

Financial disclaimers None.

\section{References}

1. Moen MD, Richter HE (2014) Vaginal hysterectomy: past, present, and future. Int Urogynecol J 25(9):1161-1165. doi:10.1007/s00192014-2459-x

2. Nieboer TE, Johnson N, Lethaby A, Tavender E, Curr E, Garry R, van Voorst S, Mol BW, Kluivers KB (2009) Surgical approach to hysterectomy for benign gynaecological disease. Cochrane Database Syst Rev 3, CD003677

3. Relph S, Bell A, Sivashanmugarajan V, Munro K, Chigwidden K, Lloyd S, Fakokunde A, Yoong W (2013) Cost effectiveness of enhanced recovery after surgery programme for vaginal hysterectomy: a comparison of pre and post-implementation expenditures. Int J Health Plann Manag. doi:10.1002/hpm.2182

4. Stovall TG, Summit RL Jr, Washburn SA, Ling FW (1994) Gonadotropin-releasing hormone agonist use before hysterectomy. Am J Obstet Gynecol 170(6):1744-1748, discussion 1748-51

5. Dawe SR, Pena GN, Windsor JA, Broeders JA, Cregan PC, Hewett PJ, Maddern GJ (2014) Systematic review of skills transfer after surgical simulation-based training. Br J Surg 101(9):1063-1076 